\title{
كيفية تلافي عيوب الطلاء الزجاجي البلوري لإثراء الأسطح الخزفية *
}

\section{إعداد}

د / وليد مصطفحـ أحمد محمد

أستاذ مسـاعد الخزف قسهم التربية الفنية كلية

التربية جامعة عين شمس التمس

ماهر حسين محمد عراقيب

باحث دكتوراه
أ . د /سلوك أحمد محمود رشلدي

أستاذ الخزف المتفرغووكيل الكلية للدراسـات العليا

$$
\begin{aligned}
& \text { والبحوث بكلية التربية النوعية- } \\
& \text { جامعة عين شمس (سابقا) } \\
& \text { ه/ سعيد عبد الغفار العنانحيـ } \\
& \text { مدرس الخزف قسهم التربية الفنية بكلية التربية }
\end{aligned}
$$$$
\text { النوعية جامعة طنطا }
$$

مجلة بحوث التربية النوعية - جامعة المنصورة

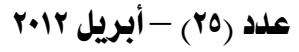


مجلة بحوث التربية النوعية - علد r - أبريل r.1r

\section{كيفية تلافي عيوب الطلاء الزجاجي البلوري لإثراء الأسطح الخرفية}

إعداد
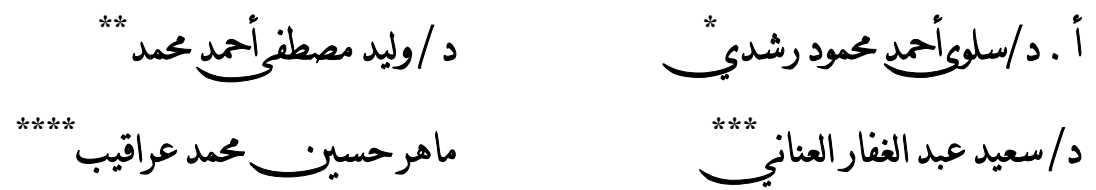

: vaill

يأتي البحث بعنوان " كيفية تلايٍ عيوب الطلاء الزجاجي البلوري لإثراء الأسطح الخزفيـة

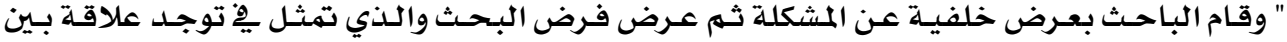

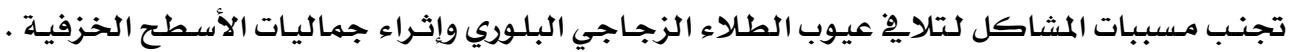

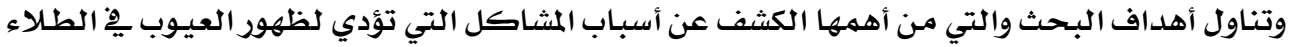

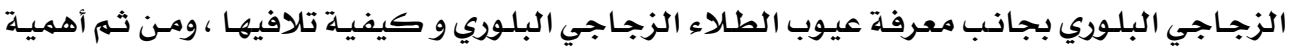

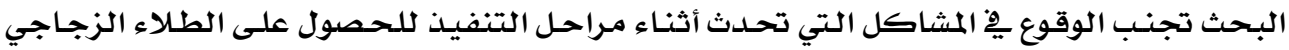

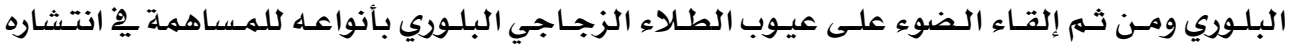

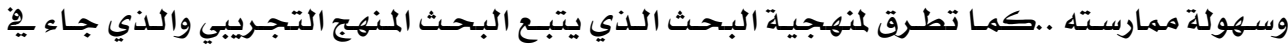
جزئين هما : الأول : الإطار النظري :أولاً:- المشاكل التي تحدث أثناء الإعداد للطلاء الزجاجي البلوري :

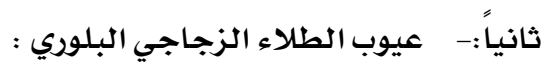

الثانى : الإطار العملي :- تانيا:

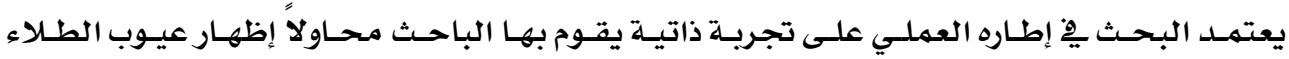

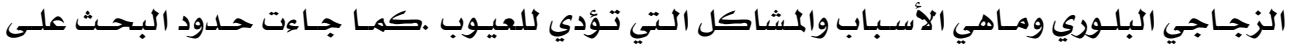

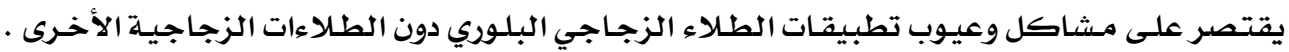

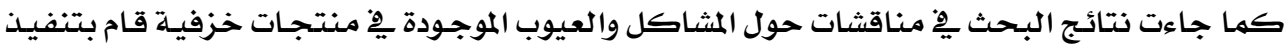

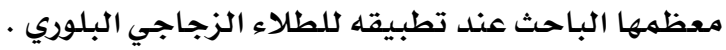

* أستاذ الخزف المتفرغ ووكيل الكلية للدراسـات العليا والبحوث بكلية التربية النوعية- جامعة عين شمس (سابقا)

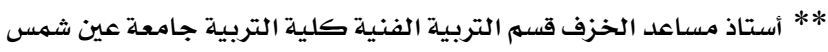
**** مدرس الخزف قسم التربية الفنية بكلية التربية النوعية جامعة طنطا باحث دكتوراه 


\title{
How To Avoid The Disadvantages Of Crystalline Glazes To Enrich The Ceramic Surfaces
}

\begin{abstract}
Summary
The search on " how to avoid the disadvantages of crystalline glaze to enrich the ceramic surfaces " and the researcher introduced the background of the problem and then view the imposition of research, which is to avoid a relationship exists between the causes of problems to avoid the disadvantages of crystal glaze and enrich the aesthetics of ceramic surfaces. And addressing the objectives of the research and most important of which reveal the causes of problems that lead to the appearance of defects in the glaze crystal next to know the disadvantages of coating glass crystal, and how to avoid them, and then the importance of research to avoid falling into the problems that occur during the implementation phases for coating glass crystal and then highlight the disadvantages of the different kinds of crystal glass paint to contribute to the spread and ease of the exercise .. also discussed the research methodology that follows Find the experimental method, which came in two parts
\end{abstract}

\section{1- Theoretical framework: -}

First : - the problems that occur during the preparation of the coating crystalline glaze .

Second : - crystalline glaze defects .

\section{2- Practical framework: -}

Supports research in which hands-on experience of self-performed by a researcher trying to show the crystalline glaze defects and what are the causes and problems that lead to defects. As it came within the limited research on the problems and disadvantages of applications glaze crystal glass coatings without the other. The results of the research in the discussions about the problems and defects in ceramic products was conducted by a researcher, most of the coating when applied to crystalline glaze . 


\section{كيفية تلافي عيوب الطلاء الزجاجي البلوري لإثراء الأسطح الخرفية}
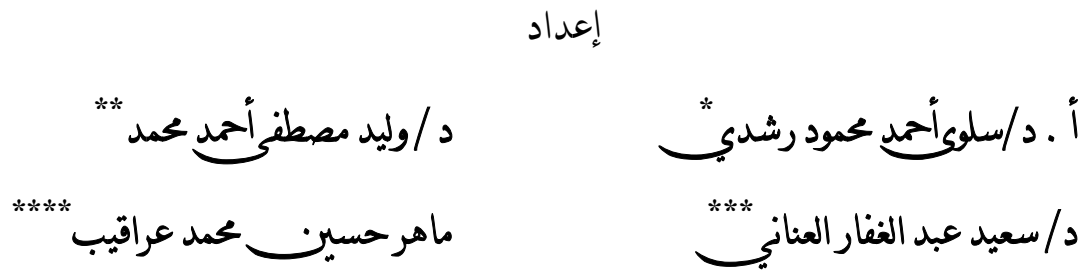

خلفية المشكلة

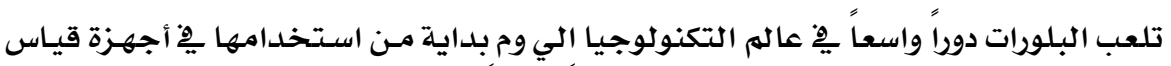

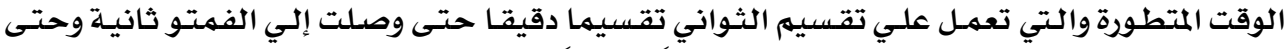

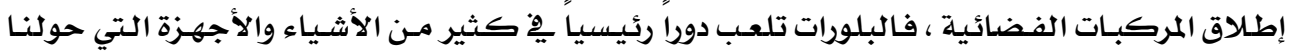

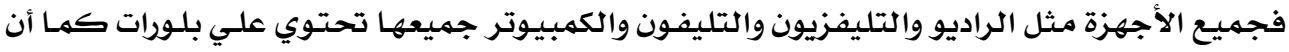

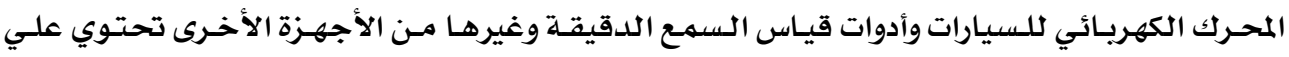
مكونات صلبة عبارة عن شرائح لبلورات منفردة .

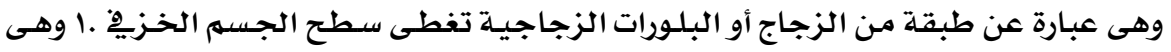

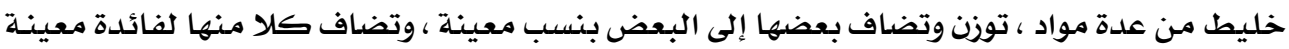

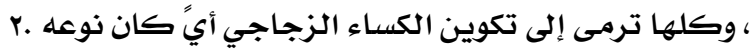

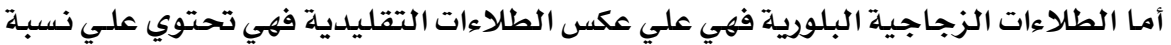

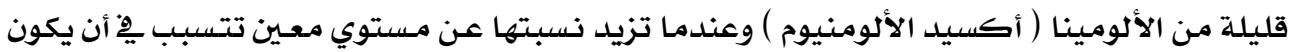

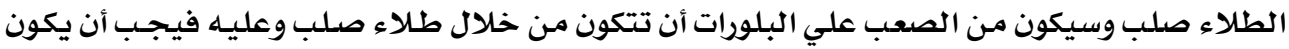

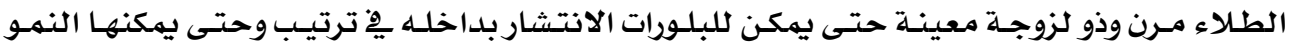
بصورة صحيحة . يعتمد النمو البلوري علي طبيعة الخامـات المكونـة للطلاء الزجاجي البلـوري ودرجـة الحـرارة

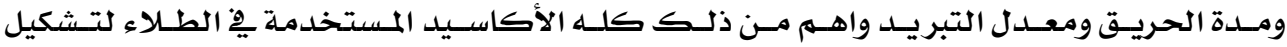

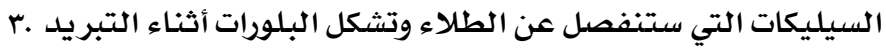

* أستاذ الخزف المتفرغ ووكيل الكلية للدراسـات العليا والبحوث بكلية التربية النوعية- جامعة عين شمس (سابقا)

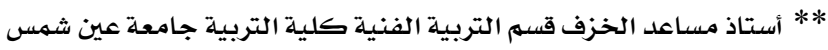

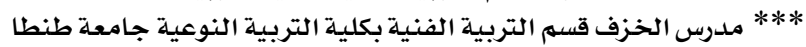
ب****** باحث دكتوراه الخزف 1 - وجيه السيد قابيل : "تكنولوجيا الطلاءات الزجاجية “،مرجـع سـابق ،ص r.

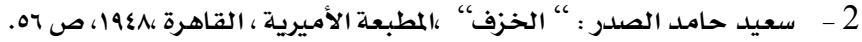

3-Cooper E., and Royle D., "Glazes for The Studio Potter” Bt Batsford Ltd London , Printed In Great Britain 1978. P113 . - 
ويعتبر الفـرن مـن الأشـياء القيمـة لـدي الخـزاف فهو ذو أهميـة كبيرة وتكلفتـه تكون أيضاً

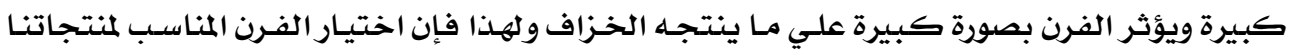

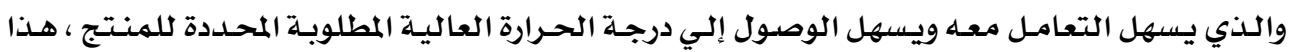

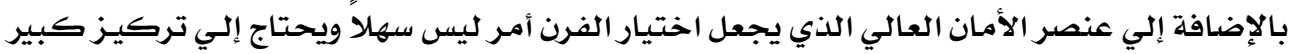

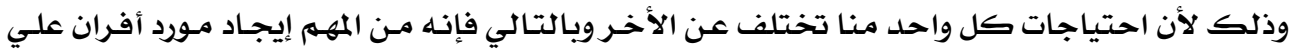

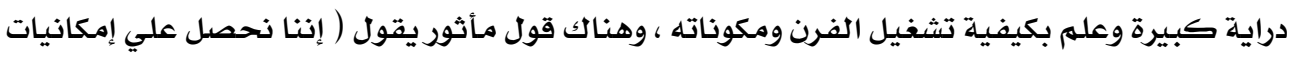

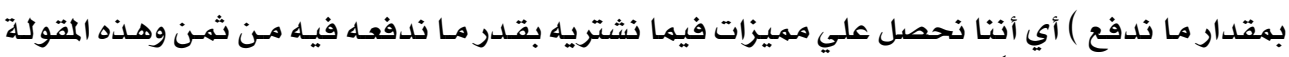

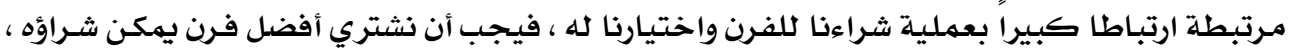

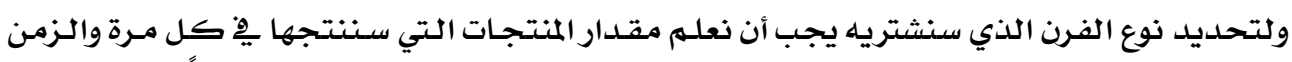

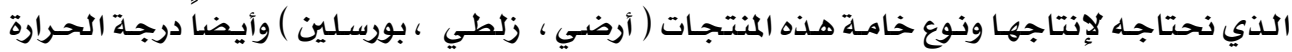

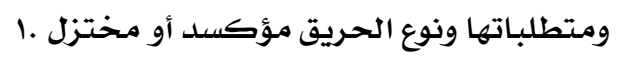

وهناك أفران بسيطة تعمل بهفتاح تشغيل فقط لفتح الفرن وغلقـه ، وهنـاك أنواع أخـري بها

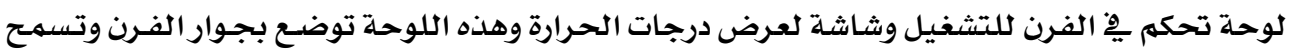

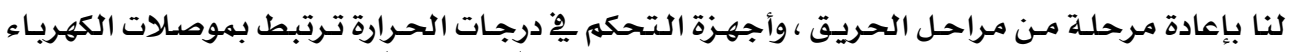

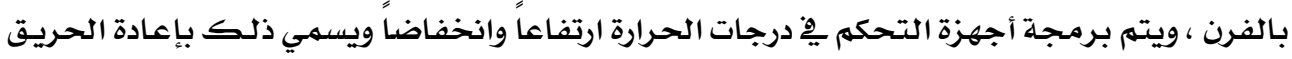

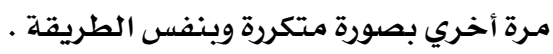

والطلاء البلوري من الطلاءات الزجاجية المستحدثة ولكنها يتتم مسن خـالال مجموعمة عمليـات

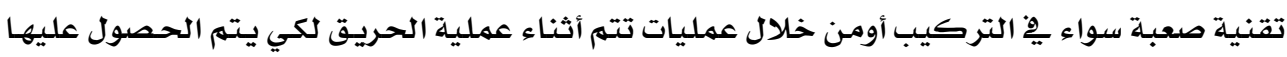

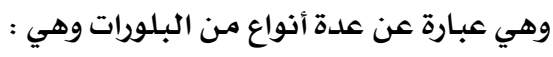

$$
\begin{aligned}
& \text { r- بلورات صغيرة الحجم . } \\
& \text { ع- بلورات متشعبـة . }
\end{aligned}
$$

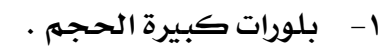

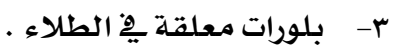

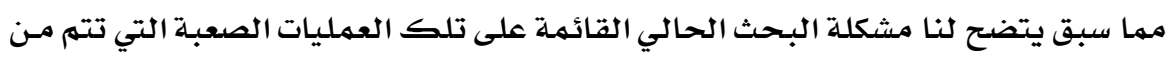

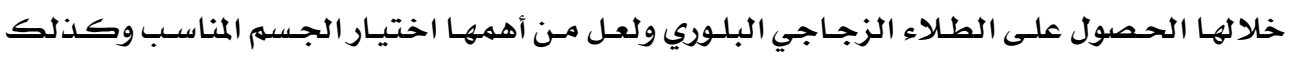

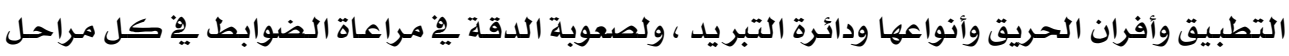

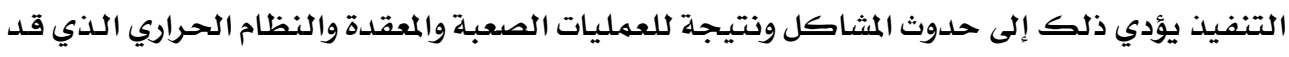

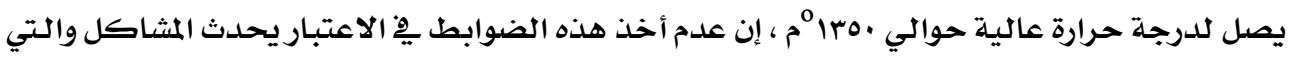

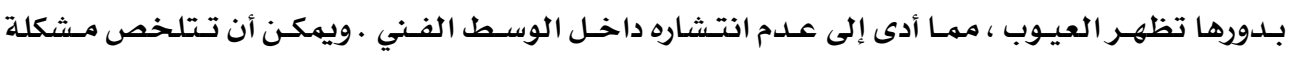

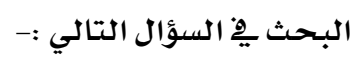

س / إلى أي مدى يمكن تلايِّ عيوب الطلاء الزجاجي البلوري يِّ إثراء الأسطح الخزفية ؟ 


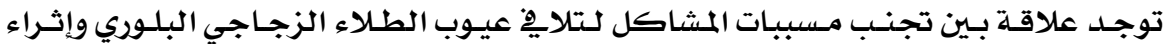

$$
\text { أودماف البحث : جأسطح الخزفية . }
$$

ا - الكشف عن أسباب المشاكل التي تؤدي لظهور العيوب يِ الطلاء الزجاجي البلوري .

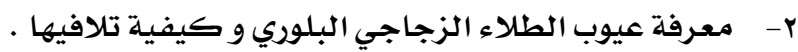

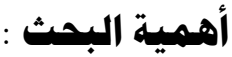

ا - تجنب الوقوع ٌِِ المشاكل التي تحدث أثناء مـراحل التتفيذ للحصول على الطلاء الزجـاجي

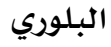

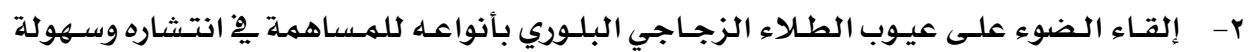

$$
\text { هنهمية البحث : ممارسته }
$$

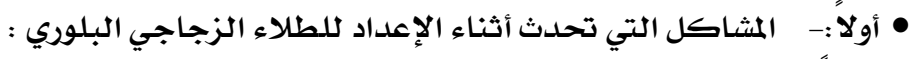

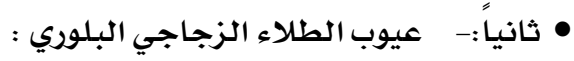

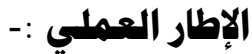

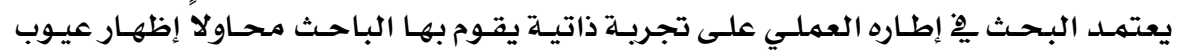

الطلاء الزجاجي البلوري وماهي الأسباب والمشاكل التي تؤدي التهلي للعيوب .

هدود البمث : -

يقتصـر البحـث علـى مـشاكل وعيـوب تطبيقـات الطـلاء الزجـاجي البلـوري دون الطـلاءات .

الزجاجية الأخرى . مان.

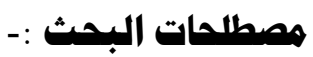

• كيفية تلافي عيوب الطلاء الزجاجي البلوري :ـ يقصد بها هنا ذكر مسببـات العيوب والمشاكل التي

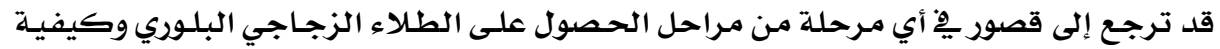

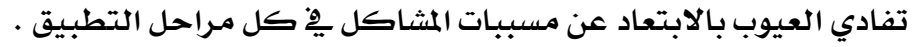

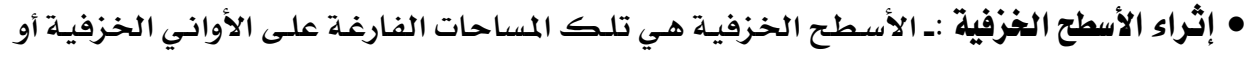

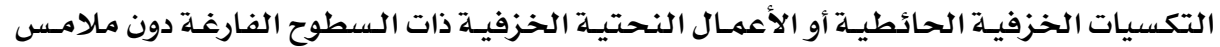

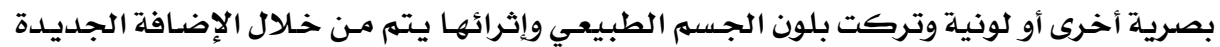

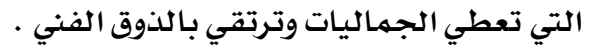


أولاً:_ المشاكل التي تحدث أثناء الإعداد للطلاء الزجاجي البلوري :

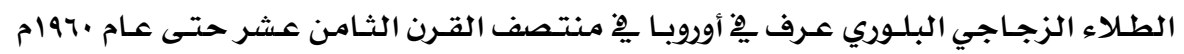

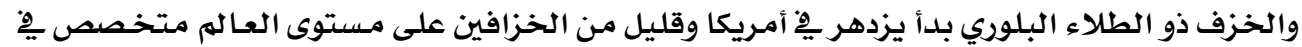

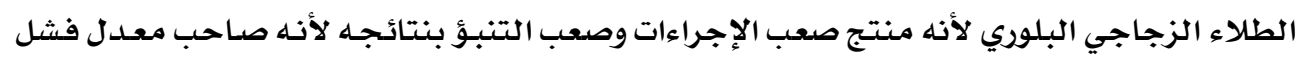

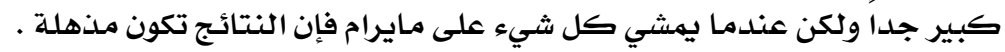

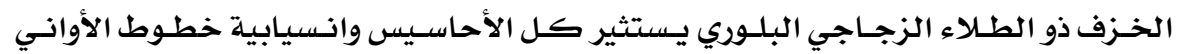

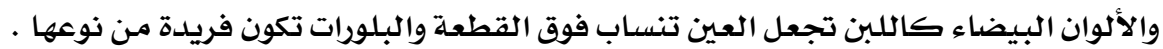

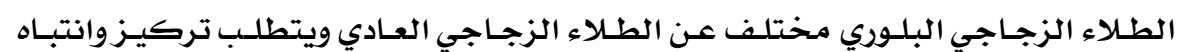

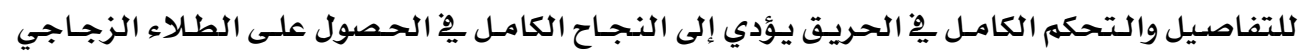

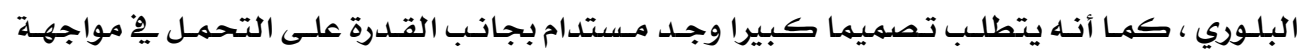

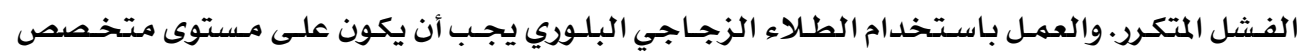

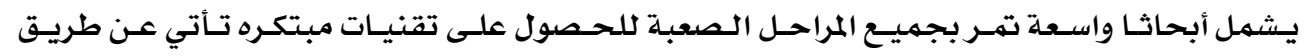

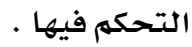

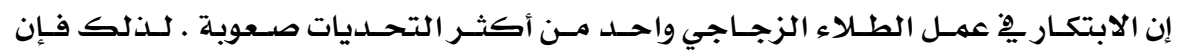

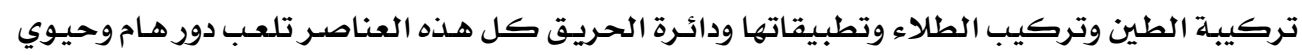

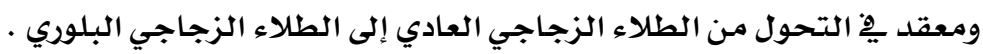

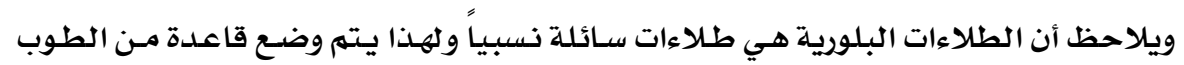

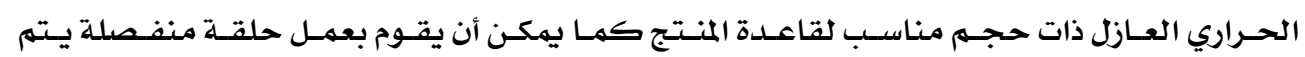

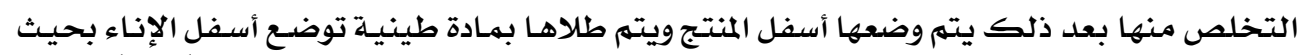

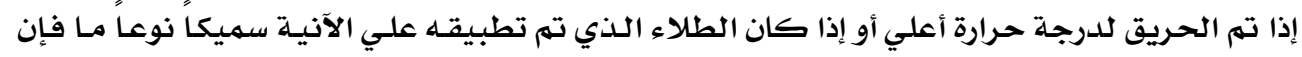

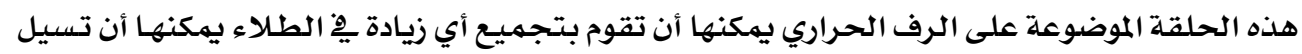

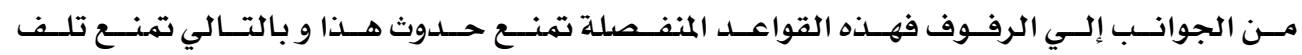

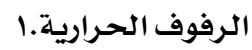

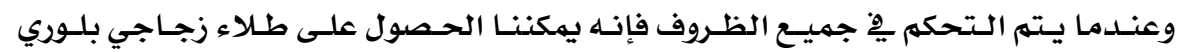

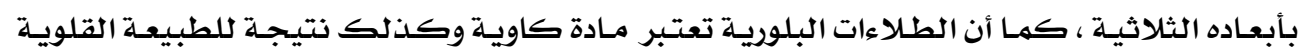

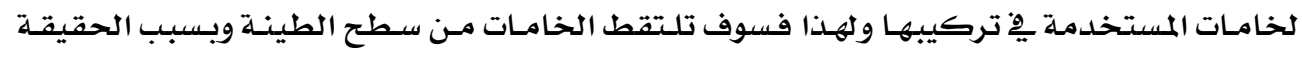

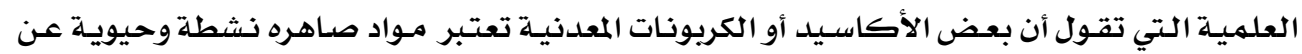

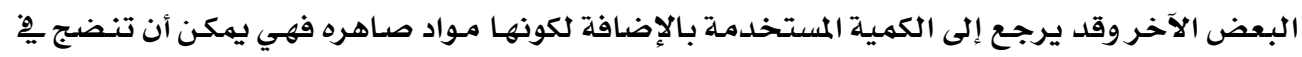

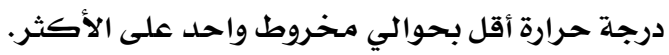

1- Nelson and Gleen C., “Ceramics And potters hand Book “, 1978. 


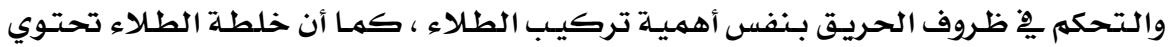

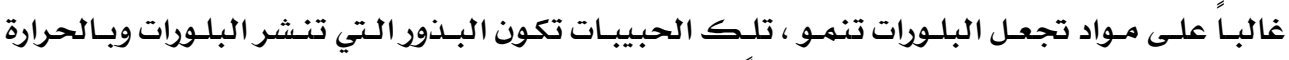

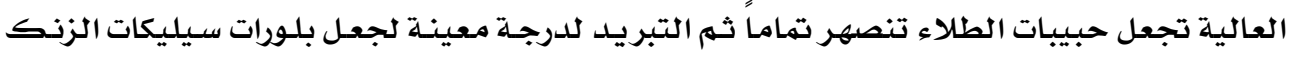

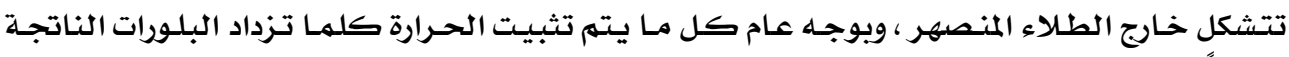

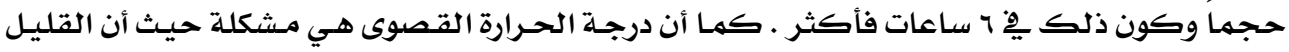

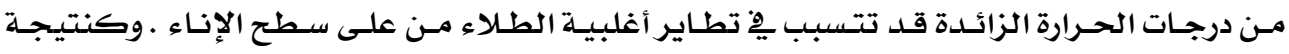

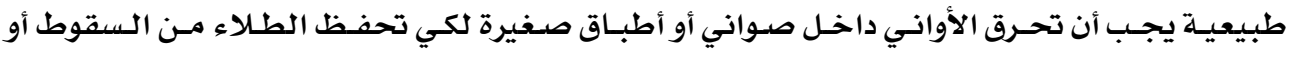

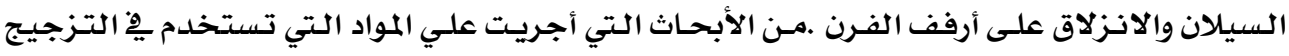

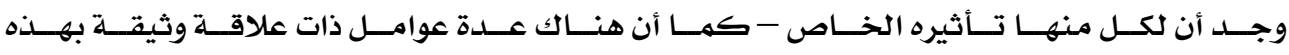

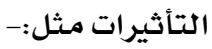

$$
\begin{aligned}
& \text { 1- مدي نعومـة مادة التزجيج · }
\end{aligned}
$$

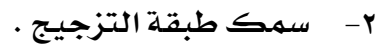

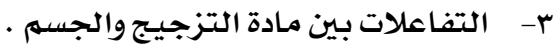

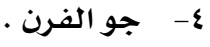

$$
\begin{aligned}
& \text { 0 - معدل التغيير عند رفع أو خفض درجة الحرارة . }
\end{aligned}
$$

وبما أنه لا يمكن مقارنة التزجيجات المختلفة بدقة إلا إذا كانت ِِّف صورة القانون المكافئ للذا

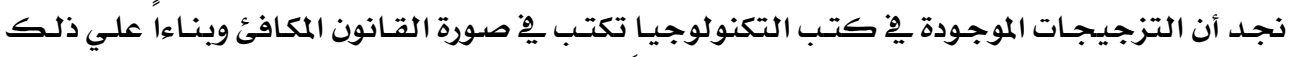

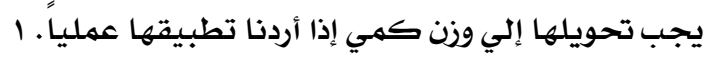

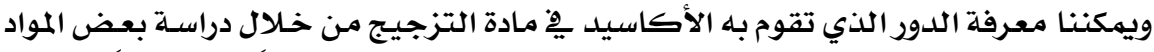

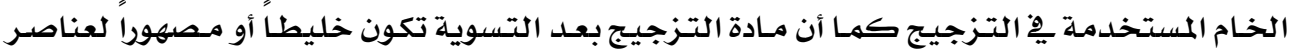

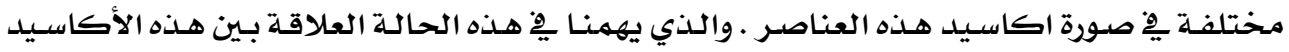

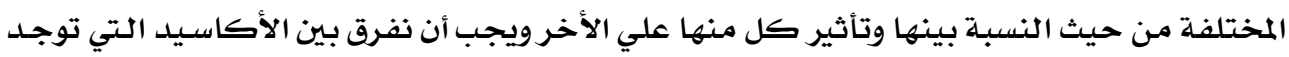

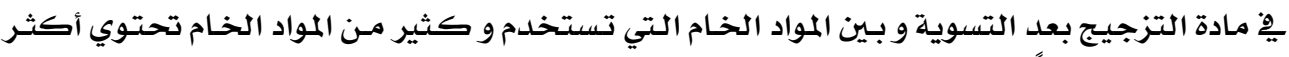

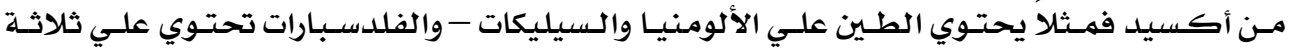

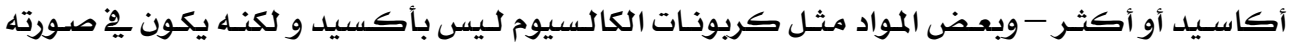

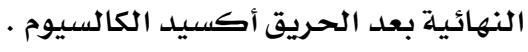

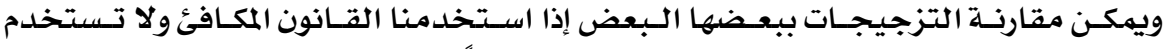

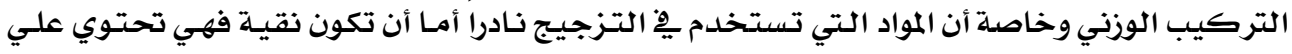

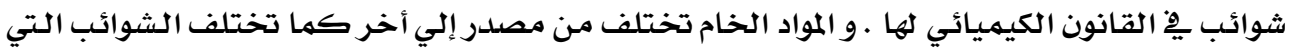
تحتويها باختلاف طريقة التنقية . 


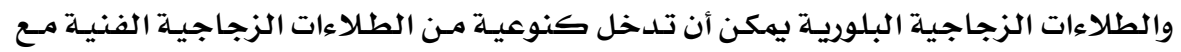

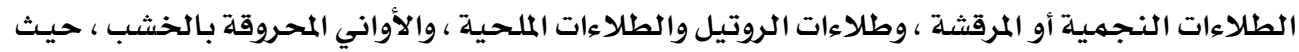

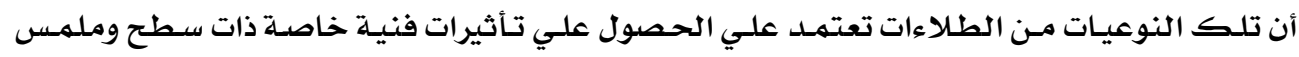

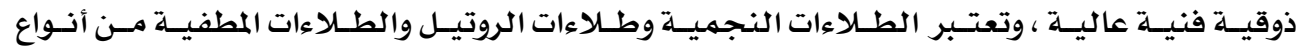
الطلاءات البلوريية البهاته

وهناك العديد من ملاحظات الفنانين التي من الممكن أن تصنع الفرق للحصول على الطلاء

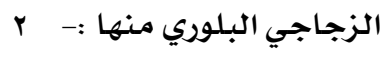

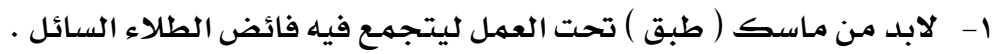

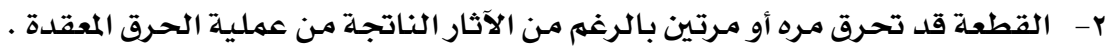

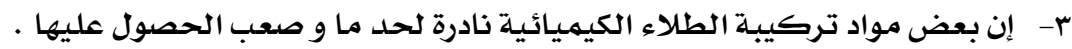

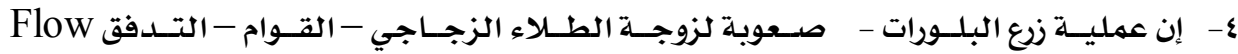

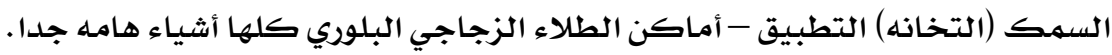

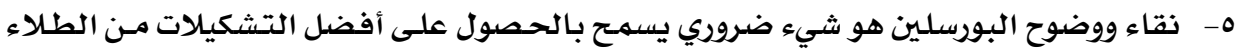

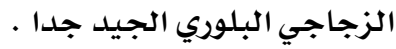

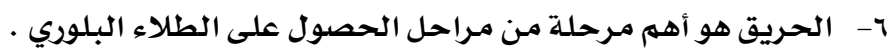

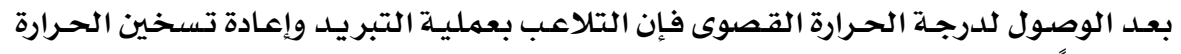

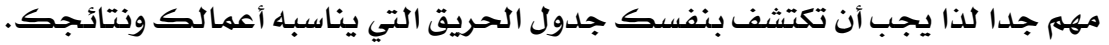

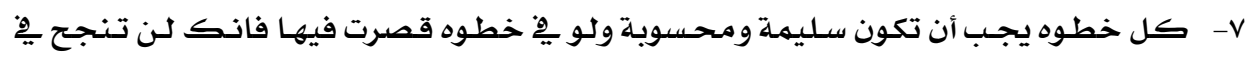
الحصول على نمو للبلورات.

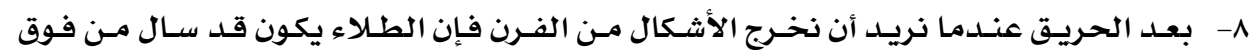

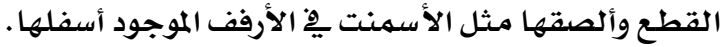

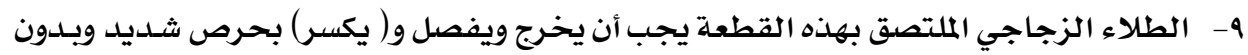

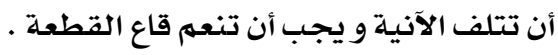

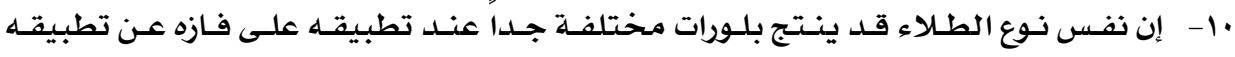

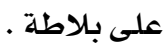

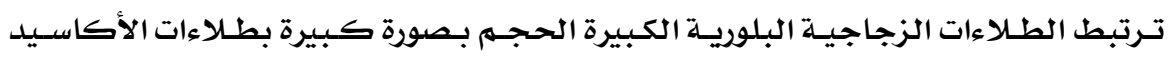

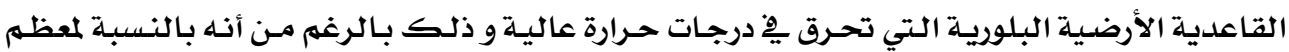

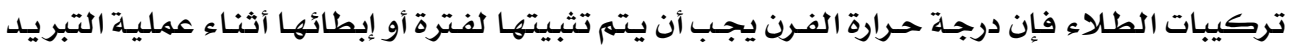

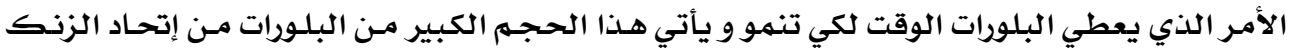

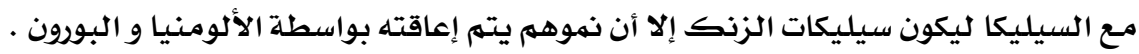

1 -ceramic review,march-april,1991.nvmber 128,p.36 2- http://www.simair.ca 
إلا أن المشكلة الكبيرة تكمن يف قلة ثبات هـذه الأكاسيد المترددة ( الألومنيا والبورون ) والتي

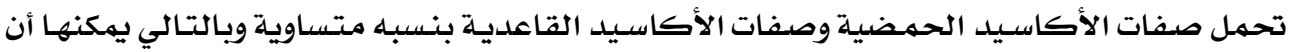

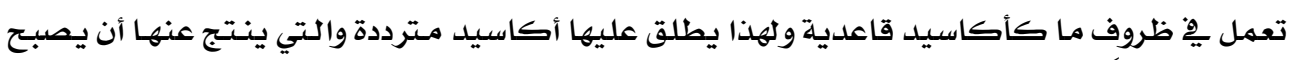

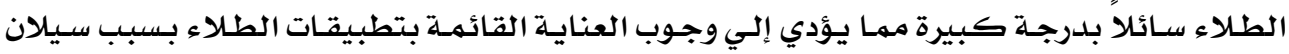

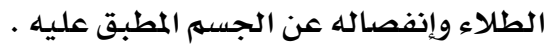

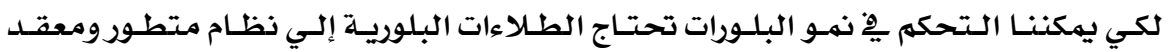

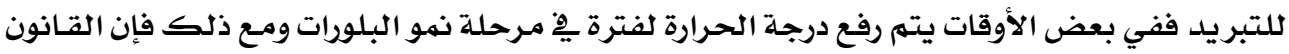

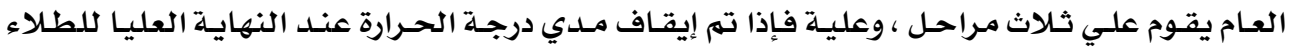

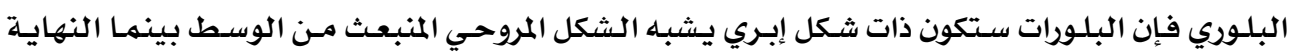
الدنيا تعطي أشكال منتظمة تشبـه الزهور .

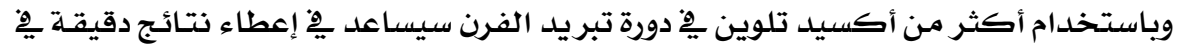

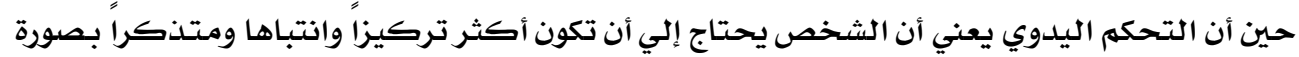

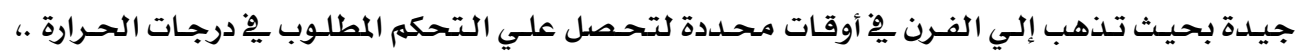

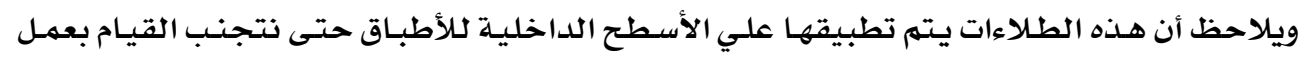

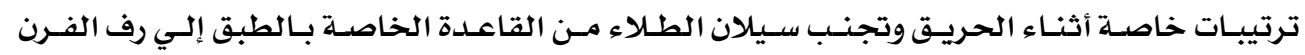

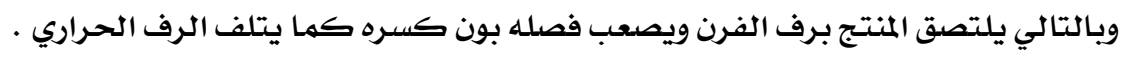

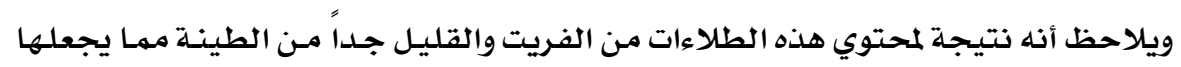

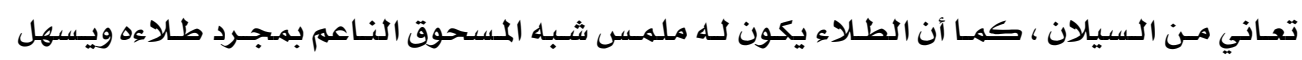

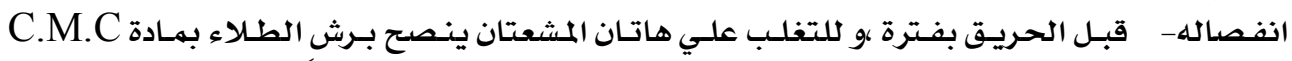

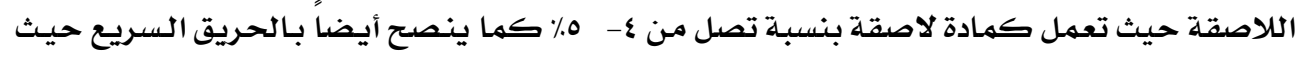
يؤدي ذلك إلي تقليل امتصاص الألومنيا من الجسهم.

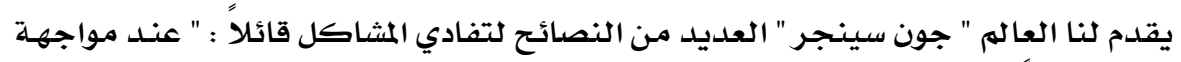

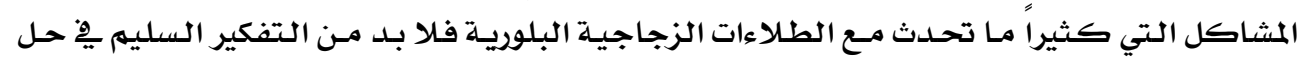

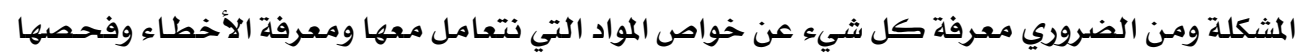

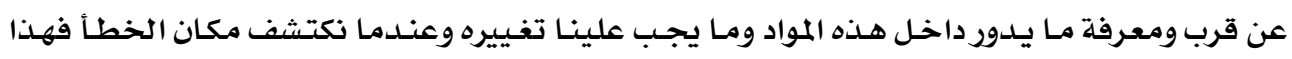

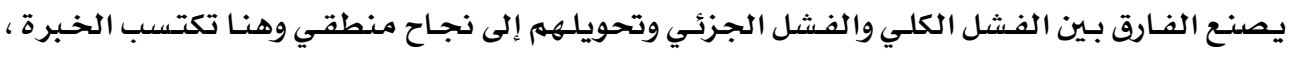

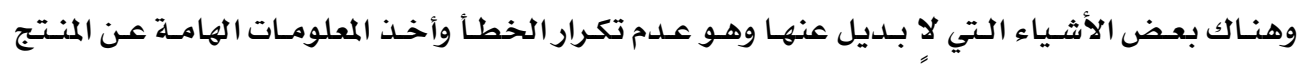

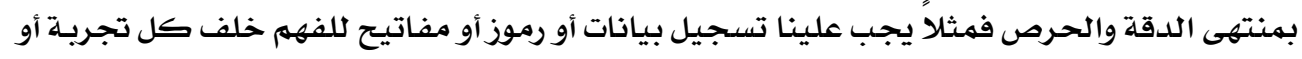

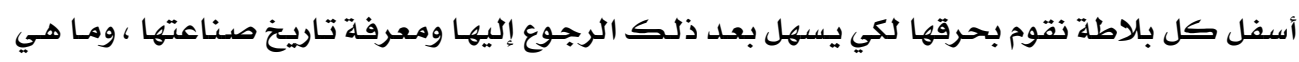

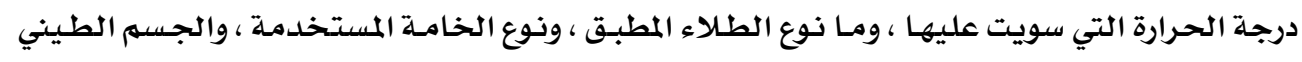




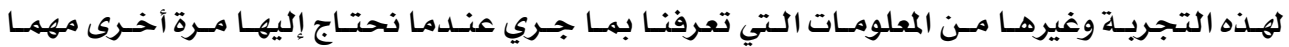
1. جرى الزمـن

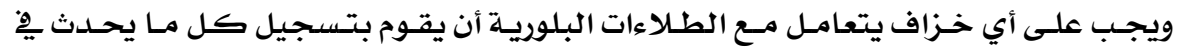

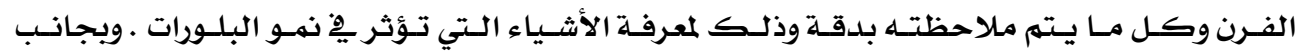

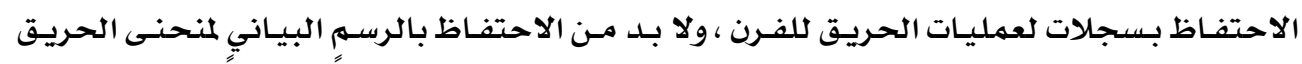

وبعتبر الرسه البياني هو أفضل وأسهل طريق كلاحتفاظ بمسار الحريق دقيقاً ومحددا

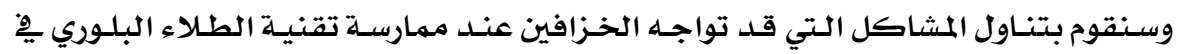

جميـع مـراحل التتفيذ وللحصصول على طلاء بلوري جيد يجب الابتعاد عن هذه المعوقات وهذه المشاكل نوجزها يِخ الآتي :

$$
\begin{aligned}
& \text { 1- مشاكل بسبب الجسلم . }
\end{aligned}
$$

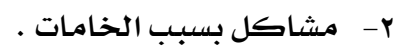

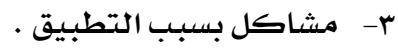

$$
\begin{aligned}
& \text { ع- مشاكل بسبب العوازل . مشاكل }
\end{aligned}
$$

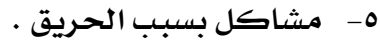

$$
\begin{aligned}
& \text { 7- مشاطل بسبب التبريد . } \\
& \text {-V }
\end{aligned}
$$

يقوم البـاحث بعرض مـا يجب مـراعاته أثناء مـراحل تنفيـ الطلاء الزجـاجي البلـوري لتجنـب

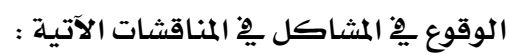

$$
\text { - مشاكل بسبب الجسيم : }
$$

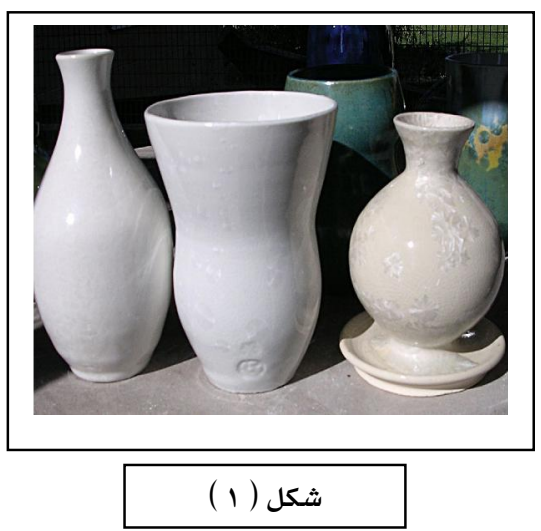

إذا كــان الجسـسم خـشن وغـير نقـي وذو دـون

غـامق أي لا يكـون أبـيض اللــون فقـــ لا نحـــل علـى بلورات حيث سيتم إعاقتها مـن السطح الخشن أو بسبـب

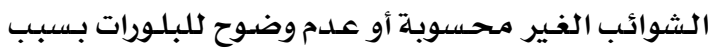
لون الجسمر ولذا فيجـب أن يكون الجسسم مـن البورسـلين

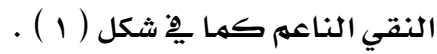

1- Fara Shimbo, Crystal Glazes by Digitalfire Corporation 2003,p42. 2- Fara Shimbo, Crystal Glazes by Digitalfire Corporation 2003,p134. 


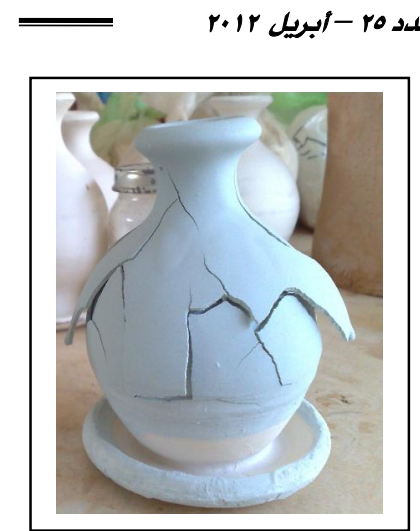

شكل (r )

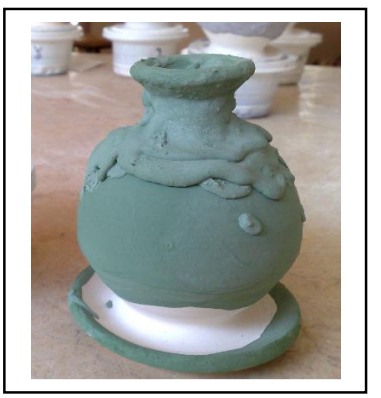

شكل (r )

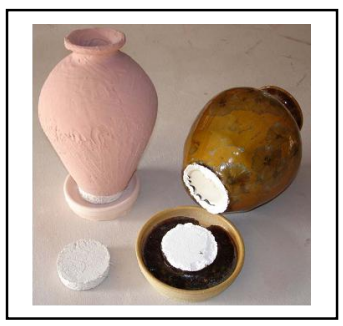

شكل (

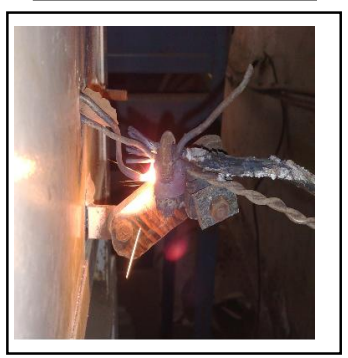

شكل ( ) ( ) r- مشاكل بسبب الخامات :

قـلد يرجسـع لحجـهم الحبيبـات فـإذا كانست الحبيبـات المـواد

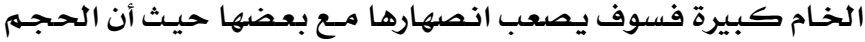

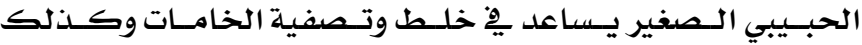

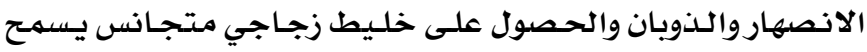
بمرور البلورات وانتشارها فيـه .

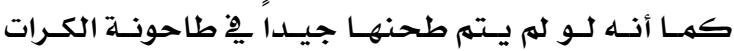

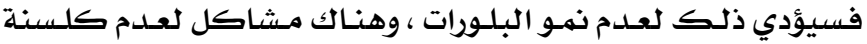

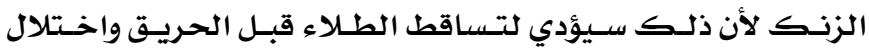

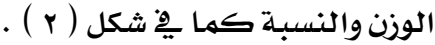
r- مشاكل بسبب التطبيق : مركب إذا كـان التطبيـق خفيـف فـلا يـشجـع ذلــك علـى ظهـور

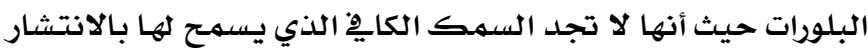

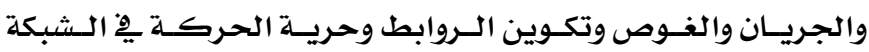

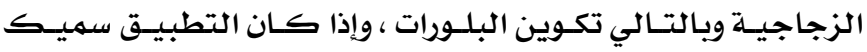
فسيكون الطلاء المسال كثير ويلتصق بالرف كمها يِّ شكل ( ب ) .

\section{ع- مشاكل بسبب العوازل :}

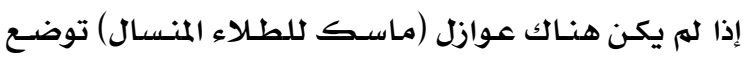

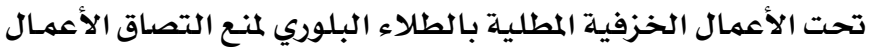

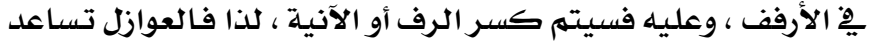

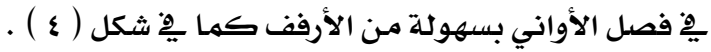

\section{0- مشاكل بسبب الحريق :}

إذا لم تصل درجـة الحـرارة لأعلى مـن درجـة الانصهار التـام

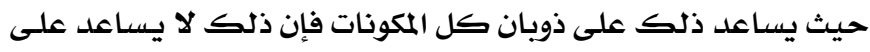

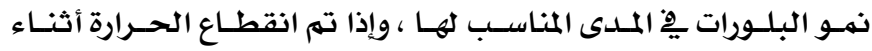

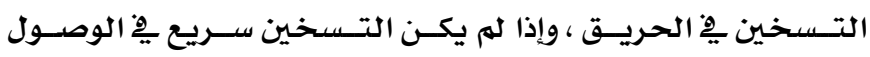

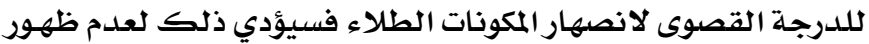

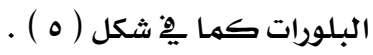




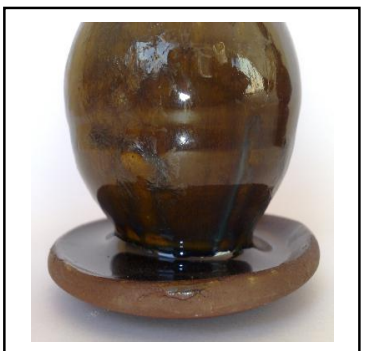

شكل (
ז- مشاكل بسبب تثبيت الحرارة وملدى التبريل :

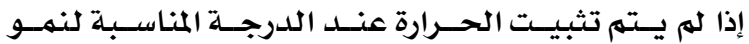

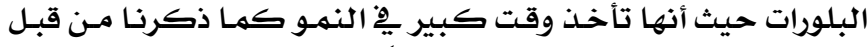

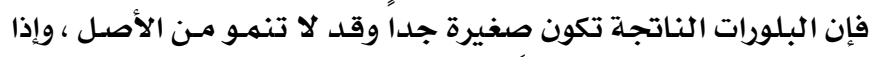

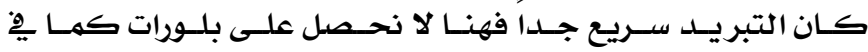
شكل (؟) . - - - v

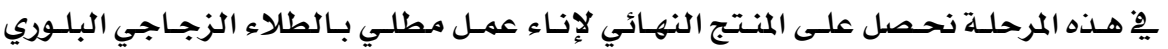

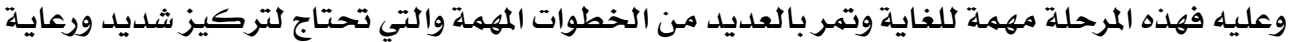

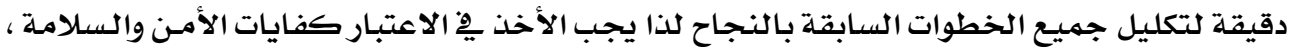

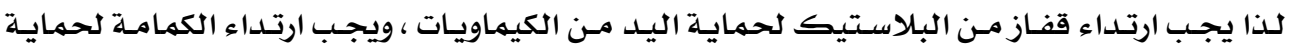

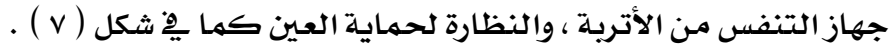

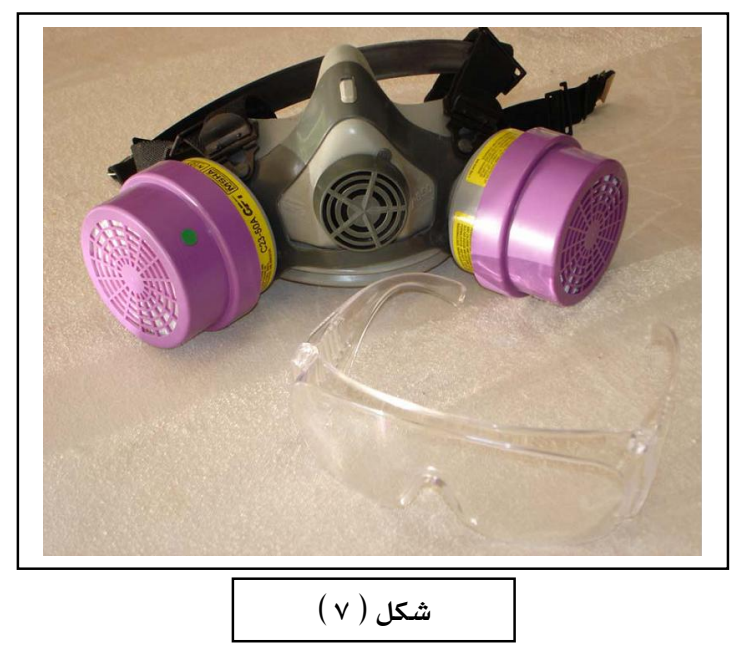

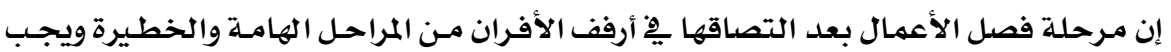

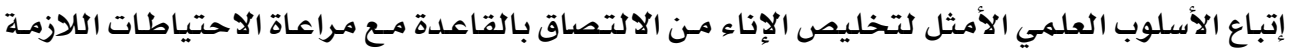

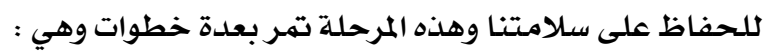

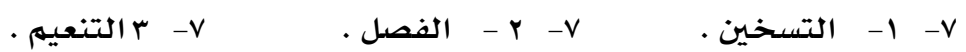

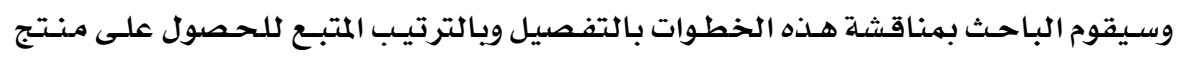

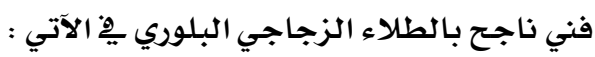




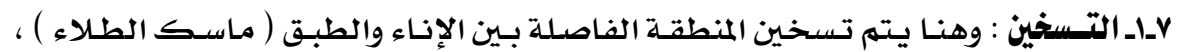

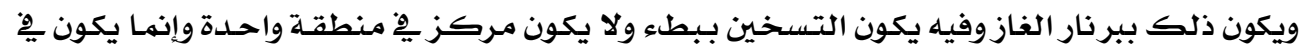
المنطقة التي حول الخط الفاصل كما فيخ شكل ( 1 ، 9 ) ) .

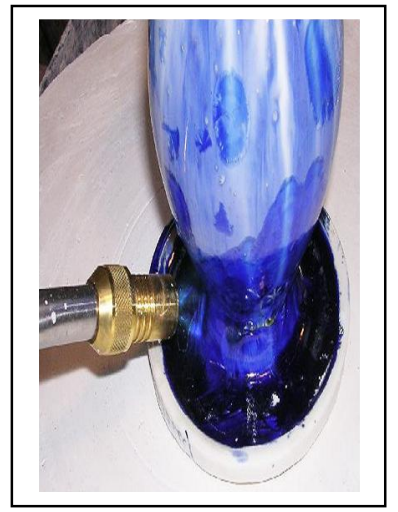

شكل (q)

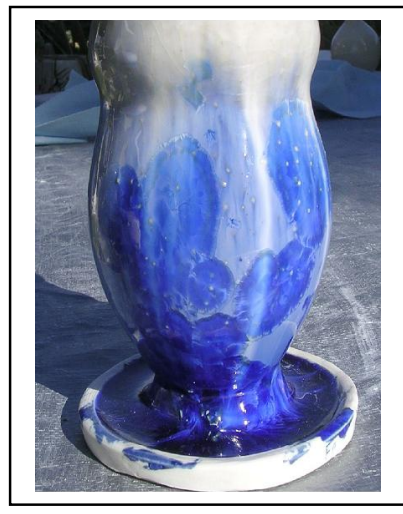

شكل ( )

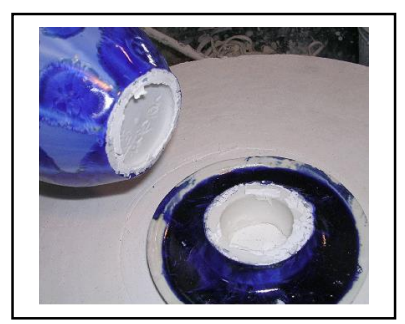

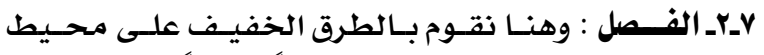

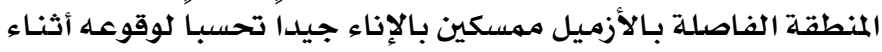

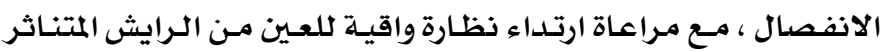

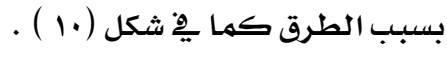

شكل (1. ) (1) )

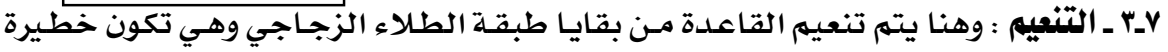

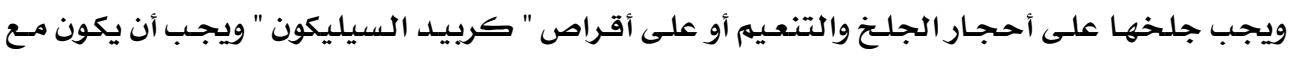

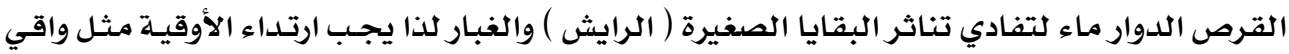

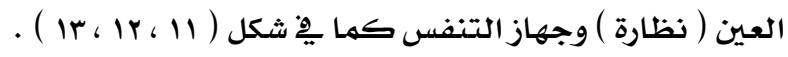
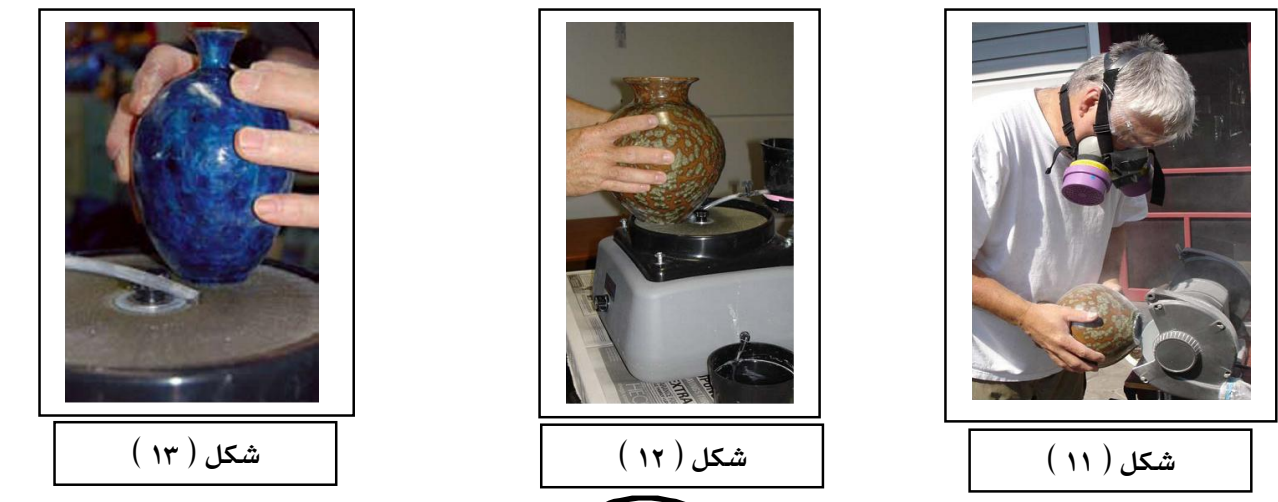

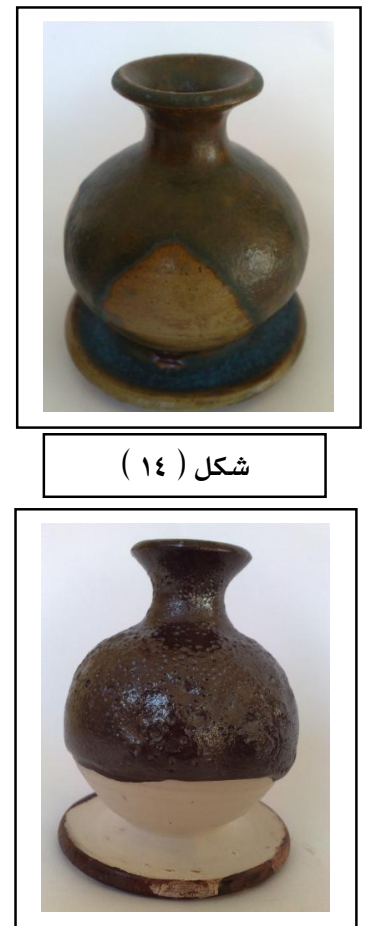

شكل (10 ) - (10)

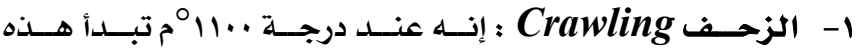

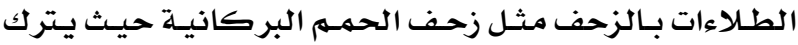

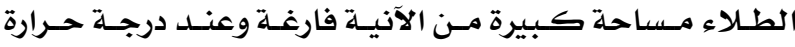

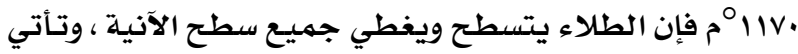

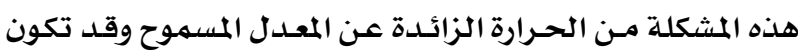

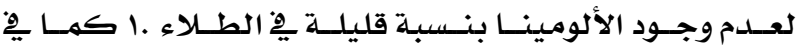

شكل (ع ا) .

r- الثقـوب الإبريــ Pinholing : والثقـوب الإبريــة الـتي توجـــ

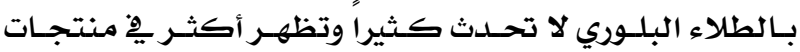
عنها يْ البورسلين وقد يكون سببـها هو طلاء جوانب الآنية بطلاء منخفض الحرارة ، فالثقوب الإبريـة تتكون

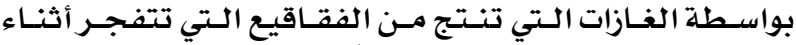
تفاعل مواد الطلاء وهو سـائل تماماً .

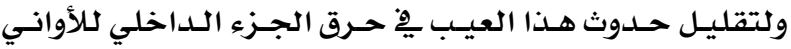

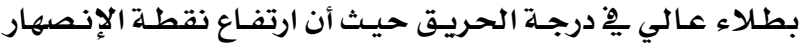

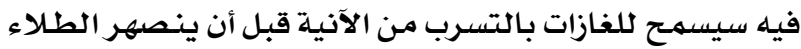

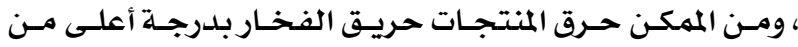

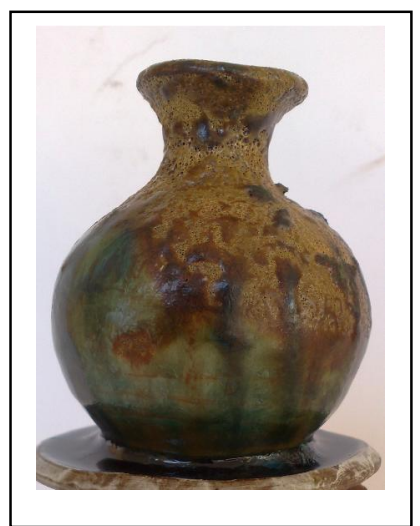

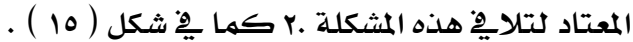

\section{: Boiling ب الغليان}

ينتجج عـن غليـان الطـلاء ثقـوب أبريـة متسعـة يطلـق عليها

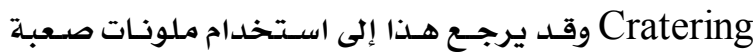

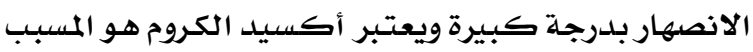

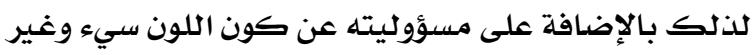

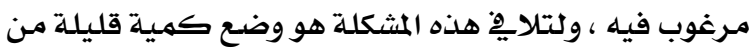

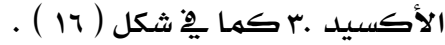

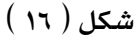

1- Fara Shimbo, Crystal Glazes by Digitalfire Corporation 2003,p148.

2 - Fara Shimbo, Crystal Glazes by Digitalfire Corporation 2003,p148.149.

3 - Fara Shimbo, Crystal Glazes by Digitalfire Corporation 2003,p149. 


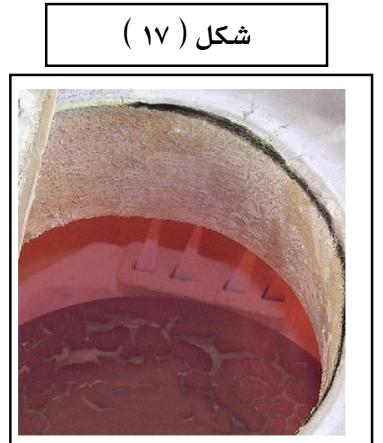

شكل ( )

\section{التجميع Assembly}

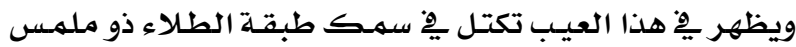

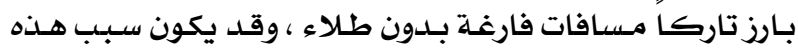

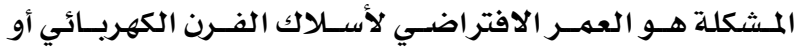

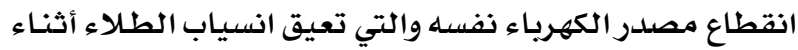

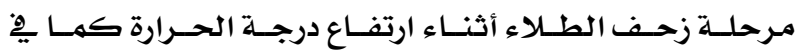
شكل (IV).

\section{ع- الطقطقة Crackling}

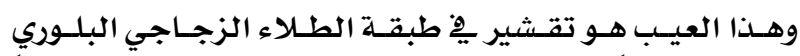

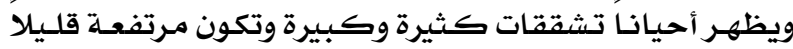

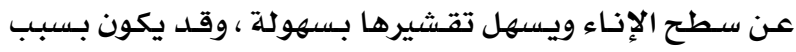

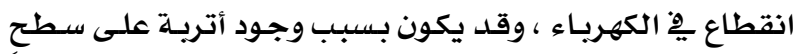

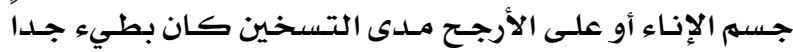

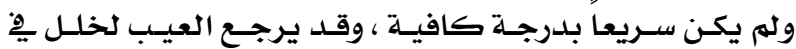

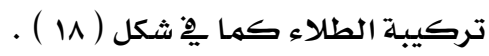

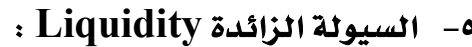

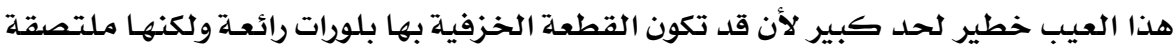

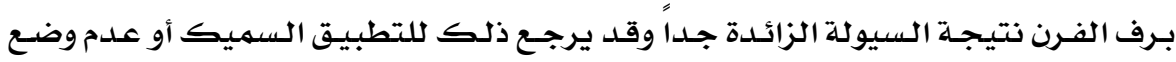

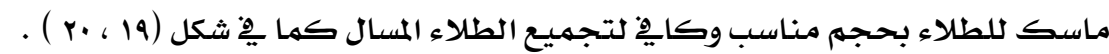

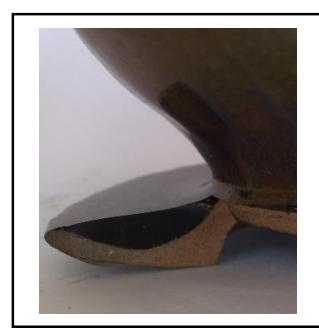

شكل ( ) (r) (1) (n)

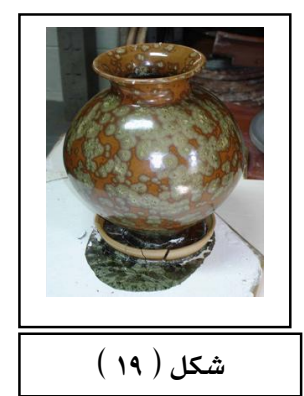




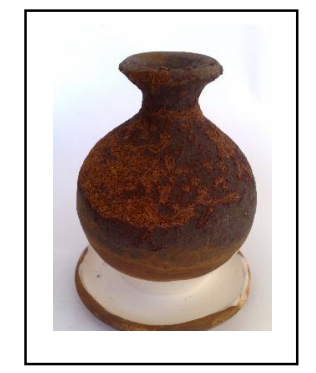

شكل ( ) (r) (1) (n)
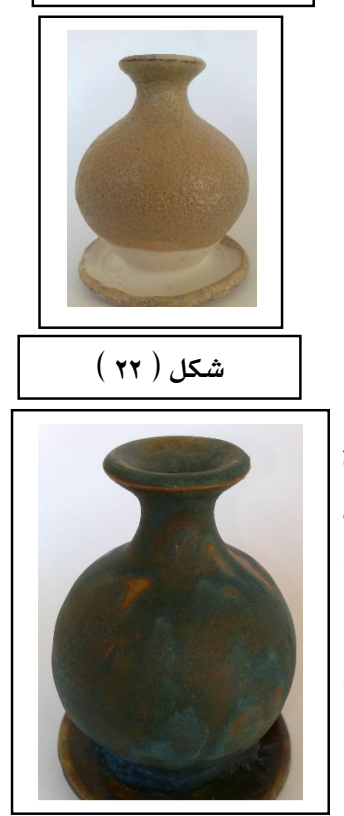

شكل ( ) ( )

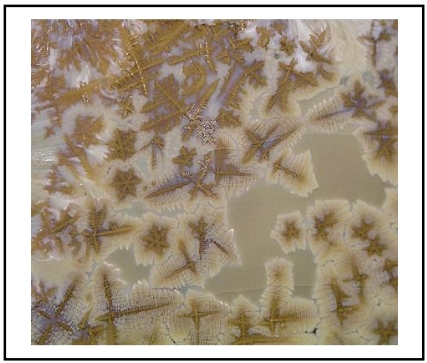

شكل ( ) (r ) (n)
צ- الخشونة Coarse Texture

هذا العيب عبارة عن ملمس خشن نحسـه بالبــر مـن بعـد ، وباليـد

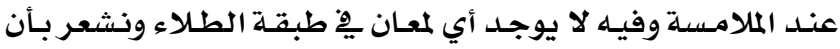

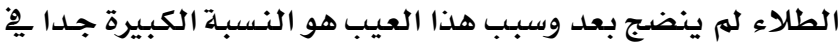

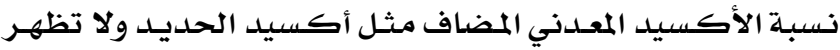

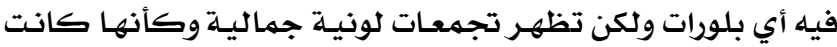

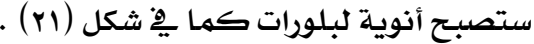

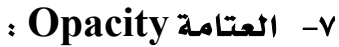

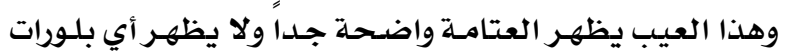

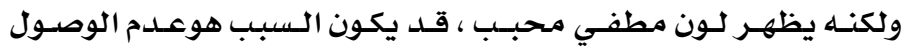

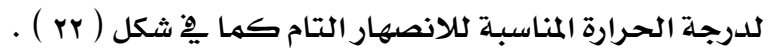

هي بلورات إبريـة مـن مركبـات كبريتيـة تظهر علـي جسـم المنتج

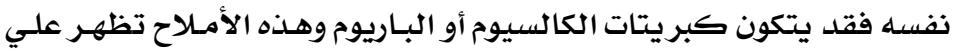

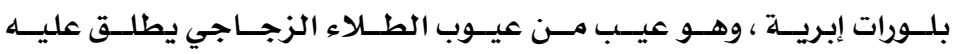

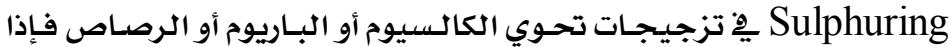

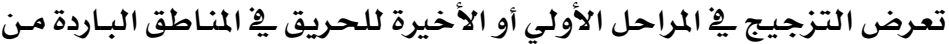

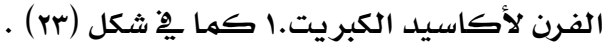

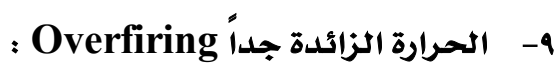

يظهـر هــذا العيـب بلــورات Natrosilite مـــع النيكـل

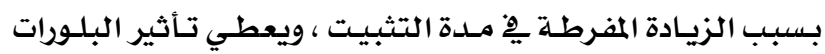

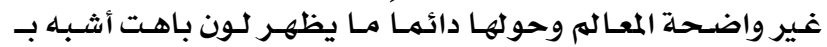

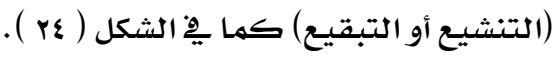

1 - - وجية السيد قابيل: مرجع سابق ، ص ·r. 


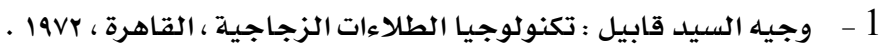

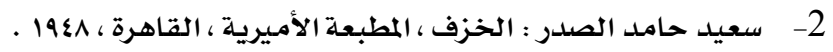

3-Cooper E., and Royle D., “Glazes for The Studio Potter” Bt Batsford Ltd London , Printed In Great Britain 1978. P113.

4 - Fara Shimbo, Crystal Glazes by Digitalfire Corporation 2003,p134.

5-Diane Creber : Crystalline Glazes , P 57, 2005 